\title{
Lung cancer, tobacco, and environmental factors in the African population of the Northern Province, South Africa
}

\author{
Olga Mzileni, Freddy Sitas, Krisela Steyn, Henri Carrara, Pieter Bekker
}

Department of

Internal Medicine,

Medical University of

South Africa,

Medunsa, Republic of

South Africa

O Mzileni

Cancer Epidemiology Unit, National Cancer Registry, Department of Anatomical

Pathology, South

African Institute for

Medical Research,

University of the

Witwatersrand,

Johannesburg

F Sitas

H Carrara

Medical Research

Council of South

Africa

K Steyn

P Bekker

Correspondence to: Dr O Mzileni, Department of Internal Medicine, Medical University of South Africa, PO Box 471,

Medunsa 0204, Republic of South Africa

mzileni@medunsa.ac.za

Received 10 November 1998 Revised 26 June 1999 Accepted 7 July 1999

\begin{abstract}
Objective-To measure the association between lung cancer and exposure to tobacco, occupational pollution, and environmental pollution.
\end{abstract}

Design-Case-control study among incident African patients with cancer. Questionnaire assessment of exposure to tobacco, occupation, and place of birth.

Setting-Northern Province, South Africa.

Subjects-Between 1993 and 1995, 288 men and 60 women with lung cancer and 183 male and 197 female controls (consisting of patients newly diagnosed with cancers other than those known to be associated with smoking) were interviewed. Unmatched, unconditional logistic regression was used to calculate odds ratios (ORs) and $95 \%$ confidence intervals (95\% CIs) of developing lung cancer in relation to a number of variables.

Main outcome measure-Risk of developing lung cancer related to exposure to tobacco, indoor pollution, dusty work environment, and residential exposure to asbestos.

Results-There was a significant increase in the risk of developing lung cancer through smoking. In men, the ORs were $2.2(95 \% \mathrm{CI}=1.0$ to 4.6$)$ in ex-smokers, 9.8 $(95 \% \mathrm{CI}=5.9$ to 16.4$)$ in light smokers $(0-14 \mathrm{~g} / \mathrm{day})$, and $12.0(95 \% \mathrm{CI}=6.5$ to 22.3$)$ in heavy smokers. In women, the ORs were $5.8(95 \% \mathrm{CI}=1.3$ to 25.8$)$ in ex-smokers and $5.5(95 \% \mathrm{CI}=2.6$ to 11.3$)$ in current smokers. Work in a dusty industry showed an elevated risk $(\mathrm{OR}=3.2,95 \% \mathrm{CI}=1.8$ to 5.8) for lung cancer only in men. Male residents of areas where asbestos was shipped for distribution (termed moderately polluted asbestos areas) had a 2.5 -fold increase $(95 \% \mathrm{CI}=1.0$ to 4.4$)$ in the risk (OR) of developing lung cancer, and residents of areas where asbestos was mined (termed heavily polluted asbestos areas) had a 2.8 -fold increase in risk $(95 \%$ $\mathrm{CI}=0.7$ to 10.4 ). Female residents of heavily polluted asbestos areas showed elevated risks of $5.4(95 \% \mathrm{CI}=1.3$ to 22.5$)$ of developing lung cancer.

Conclusion-The data suggest that tobacco smoking is the most important risk factor for the development of lung cancer in this setting. Risks for lung cancer are reminiscent of those observed in Western countries in the 1960 s and 1970 s. However, environmental exposure to asbestos, a dusty occupation (in men), and perhaps indoor air pollution may also contribute to the development of lung cancer in this province.

(Tobacco Control 1999;8:398-401)

Keywords: lung cancer; tobacco smoking; South Africa

\section{Introduction}

Although the relation between tobacco and lung cancer has been reasonably well described in developed countries, ${ }^{1}$ little or no data are available in sub-Saharan African populations where cigarette smoking is a more recent phenomenon and where population life expectancy is low. In one study among African men in Bulawayo between 1963 and $1977^{2}$ lung cancer was five times more common in smokers of $15 \mathrm{~g}$ of tobacco or more. Aside from this study, no recent data on lung cancer are available for African populations in relation to environmental, occupational dust exposure-for example, asbestos - and fuel use in the home.

Northern Province (covering the area just north of the capital city of Pretoria up to the Zimbabwe border) is one of the poorest provinces in South Africa. Life expectancy and annual per capita income are below the national average (62.7 $v 63.4$ years; US $\$ 145 v$ $\$ 500$ ) and so are many other health indicators. ${ }^{3}$ In 1995, in the Northern Province, 38\% of African men and $2.1 \%$ of women were current smokers. In the same study the national current smoker average for African men and women was $53 \%$ and $10 \%{ }^{4}$

The Northern Province is also an important source of amosite and crocidolite asbestos. Intensive mining operations and poor environmental controls have resulted in many areas being polluted by uncontrolled dumping and subsequent use of asbestos-contaminated residual ore-for example, mixed with cement for plastering of houses. ${ }^{5}$ Ten mines were active in the $1970 \mathrm{~s}^{6}$ but all have now closed. Recent data from a regional cancer registry (1991-1994) in a rural area of this province (Elim hospital) showed world-standardised lung cancer incidence rates to be low, $11.6 / 100000$ in men and non-existent $(0 / 100000)$ in women. ${ }^{7}$ One male and one female were registered with a mesothelioma in this period (unpublished data), suggesting some degree of exposure to asbestos in this population. 
Table 1 Association between smoking, environmental and occupational pollution, and lung cancer in the Northern Province, South Africa

\begin{tabular}{|c|c|c|c|c|c|c|c|}
\hline & $\begin{array}{l}\text { Cases } \\
(n)\end{array}$ & $\begin{array}{l}\text { Cases } \\
(\%)\end{array}$ & $\begin{array}{l}\text { Controls } \\
\text { (n) }\end{array}$ & $\begin{array}{l}\text { Controls } \\
(\%)\end{array}$ & $\begin{array}{l}\text { Total } \\
\text { (n) }\end{array}$ & $O R$ & $95 \% C I$ \\
\hline \multicolumn{8}{|l|}{ Males } \\
\hline \multicolumn{8}{|l|}{ Smoking status ${ }^{\star}$} \\
\hline Never & 34 & $(11.8)$ & 103 & $(56.3)$ & 137 & 1.0 & Referent \\
\hline Ex-smoker & 17 & $(5.9)$ & 20 & $(10.9)$ & 37 & 2.2 & $1.0-4.6$ \\
\hline Current & 237 & $(82.2)$ & 60 & (32.7) & 297 & 10.7 & $6.6-17.3$ \\
\hline$<15$ g/day & 135 & $(46.8)$ & 40 & $(21.9)$ & 175 & 9.8 & $5.9-16.4$ \\
\hline$\geqslant 15 \mathrm{~g} /$ day & 96 & (33.3) & 18 & $(9.8)$ & 114 & 12.0 & $6.5-22.3$ \\
\hline Not specified & 6 & $(2.1)$ & 2 & $(1.1)$ & 8 & & \\
\hline Total & 288 & $(100.0)$ & 183 & $(100.0)$ & 471 & & \\
\hline$\chi^{2}(\mathrm{p}$ trend $)$ & & & & & & 92.8 & $(0.0001)$ \\
\hline \multicolumn{8}{|l|}{ Industryt } \\
\hline Not dusty & 22 & & 43 & & 65 & 1.0 & Referent \\
\hline Dusty & 266 & $(92.3)$ & 140 & $(76.5)$ & 406 & 3.2 & $1.8-5.8$ \\
\hline$\chi^{2}(\mathrm{p}$ trend $)$ & & & & & & 15.1 & $(0.0001)$ \\
\hline \multicolumn{8}{|c|}{ Wood/coal in housef } \\
\hline No & 28 & & 25 & & 53 & 1.0 & Referent \\
\hline Yes & 260 & $(90.3)$ & 158 & $(86.3)$ & 418 & 1.9 & $0.9-3.3$ \\
\hline$\chi^{2}(p$ trend $)$ & & & & & & 2.3 & $(0.1)$ \\
\hline \multicolumn{8}{|c|}{ Asbestos exposure current residence $\$$} \\
\hline None & 218 & $(78.9)$ & 161 & $(88.0)$ & 379 & 1.0 & Referent \\
\hline Moderate & 38 & $(13.8)$ & 11 & $(6.0)$ & 49 & 2.1 & $1.0-4.4$ \\
\hline Heavy & 10 & $(3.6)$ & 3 & $(1.6)$ & 19 & 2.8 & $0.7-10.4$ \\
\hline Not specified & 10 & (3.6) & 8 & $(4.4)$ & 18 & 5.7 & $(0.02)$ \\
\hline$\chi^{2}(p$ trend $)$ & & & & & & 5.7 & $(0.2)$ \\
\hline \multicolumn{8}{|c|}{ Asbestos exposure at birth $\S$} \\
\hline None & 173 & $(60.1)$ & 134 & $(73.2)$ & 307 & 1.0 & Referent \\
\hline Moderate & 35 & $(12.1)$ & 9 & $(4.9)$ & 44 & 2.9 & $1.2-6.7$ \\
\hline Heavy & 8 & $(2.8)$ & 2 & $(1.1)$ & 10 & 3.1 & $0.4-21.4$ \\
\hline Not specified & 72 & $(25.0)$ & 38 & $(20.1)$ & 110 & & \\
\hline$\chi^{2}(\mathrm{p}$ trend $)$ & & & & & & 7.5 & $(0.006)$ \\
\hline \multicolumn{8}{|l|}{ Women } \\
\hline \multicolumn{8}{|l|}{ Smoking* } \\
\hline Never & 32 & $(53.3)$ & 190 & $(96.5)$ & 222 & 1.0 & Referent \\
\hline Ex-smoker & 4 & $(6.7)$ & 2 & $(1.0)$ & 6 & 5.8 & $1.3-25.8$ \\
\hline Current & 24 & $(4.0)$ & 5 & $(2.5)$ & 29 & 5.5 व & $2.6-11.3$ \\
\hline$<15 \mathrm{~g} /$ day & 15 & $(25.0)$ & 4 & $(2.0)$ & 19 & & \\
\hline$\geqslant 15 \mathrm{~g} /$ day & 8 & (13.3) & 0 & $(0.0)$ & 8 & & \\
\hline Not specified & 1 & $(1.7)$ & 1 & $(0.5)$ & 2 & & \\
\hline Total & 60 & $(100)$ & 197 & $(100)$ & 257 & & \\
\hline$\chi^{2}(\mathrm{p}$ trend $)$ & & & & & & 31.3 & $(0.0001)$ \\
\hline \multicolumn{8}{|l|}{ Industryt } \\
\hline Not dusty & 17 & & 37 & & 54 & 1.0 & Referent \\
\hline Dusty & 43 & $(71.6)$ & 160 & $(81.2)$ & 203 & 0.5 & $0.3-1.1$ \\
\hline$\chi^{2}(\mathrm{p}$ trend $)$ & & & & & & 2.6 & $(0.1)$ \\
\hline \multicolumn{8}{|l|}{ Wood/coal fuel $\neq$} \\
\hline No & 9 & & 41 & & 50 & 1.0 & Referent \\
\hline Yes & 51 & $(85.0)$ & 156 & $(79.2)$ & 207 & 1.4 & $0.6-3.2$ \\
\hline$\chi^{2}(\mathrm{p}$ trend $)$ & & & & & & 0.5 & $(0.5)$ \\
\hline \multicolumn{8}{|c|}{ Asbestos exposure current residence $₫$} \\
\hline None & 45 & $(75.0)$ & 180 & $(91.4)$ & 225 & 1.0 & Referent \\
\hline Moderate & 4 & $(6.7)$ & 11 & $(5.6)$ & 15 & 1.1 & $0.3-3.9$ \\
\hline Heavy & 6 & $(10.0)$ & 4 & $(2.0)$ & 10 & 5.4 & $1.3-22.5$ \\
\hline Not specified & 5 & $(8.3)$ & 2 & $(1.0)$ & 7 & & \\
\hline$\chi^{2}(\mathrm{p}$ trend $)$ & & & & & & 5.2 & $(0.02)$ \\
\hline \multicolumn{8}{|c|}{ Asbestos exposure at birth $\$$} \\
\hline None & 36 & $(60.0)$ & 162 & $(82.2)$ & 198 & 1.0 & Referent \\
\hline Moderate & 2 & $(3.3)$ & 8 & $(4.1)$ & 10 & & \\
\hline Heavy & 3 & $(5.0)$ & 0 & $(0.0)$ & 3 & $2.4^{\star \star}$ & $0.7-7.9$ \\
\hline Not specified & 19 & $(31.7)$ & 27 & (13.7) & 46 & & \\
\hline$\chi^{2}(\mathrm{p}$ trend $)$ & & & & & & 1.9 & $(0.2)$ \\
\hline
\end{tabular}

$\star$ Adjusted for age $(<55, \geqslant 55$ years), dusty occupation, and exposure to asbestos at birth.

†Adjusted for age $(<55, \geqslant 55$ years), smoking (never-smoker, ex-smoker, current specified), and asbestos exposure at birth.

†Adjusted for smoking (never-smoker, ex-smoker, current specified), dusty industry, and residential asbestos exposure.

§Adjusted for smoking (never-smoker, ex-smoker, current specified), and dusty industry.

TData for current unspecified, light and heavy female smokers were combined.

${ }^{\star \star}$ Data for females born in moderate and heavy asbestos districts were combined.

The aim of this study was to measure the risk (odds) of developing lung cancer related to tobacco smoking, fuel use, and residential and occupational exposure to dust and asbestos in the Northern Province.

\section{Methods}

A case control study was conducted between 1993 and 1995 at Garankuwa hospital, which is the main tertiary referral hospital for patients with cancer in the Northern Province. Cases consisted of 288 incident male and 60 female patients with lung cancer. Controls, selected at the same time as the cases, consisted of 183 men and 197 women diagnosed for the first time with cancers believed to be unrelated to tobacco consumption (predominantly prostate, liver, breast, colorectal, and haematological cancers). This group of cancer controls has been shown to be a useful control group in other studies. ${ }^{28}$ Sixty-one per cent of lung cancer cases and $89 \%$ of controls were diagnosed clinically and confirmed by cytology, histology, or haematology. The greater proportion of controls confirmed by microscopy is because of the inclusion of haematological cancers, all of which have to be diagnosed by haematology or histology, and breast cancers, which are reasonably easy to access. Of the 340 patients with lung cancer, 91 had squamous cell cancer and 70 had adenocarcinoma.

An interviewer questioned patients in their language of choice (usually Sotho, Venda, or Tsonga-questionnaire available on request) on basic demographic details, smoking habits (converted into approximate grammes of tobacco smoked per day), place of birth, current residence, their main occupation, and fuel use (wood and coal) at home. Industries were coded using the Central Statistical Services' manual on occupational and industrial divisions ${ }^{9}$ and patients classified as to whether they had ever worked in potentially dusty industries (includes mining, metal, nonmetallic mineral products, and quarrying). Postal codes of places of current residence and place of birth were used to classify areas into heavy asbestos (areas where mining took place), moderate asbestos (towns where raw asbestos was transferred from the mines for shipping to other areas), and none. Subjects were not asked whether they worked with asbestos or in dusty occupations to avoid any possible recall biases over the reporting of these exposures.

Unconditional unmatched logistic regression models ${ }^{10}$ were used to calculate odds ratios (ORs) and 95\% confidence intervals (95\% CIs) of developing lung cancer, after controlling, as appropriate, for a number of variables (table 1).

Adjustment variables consisted of tobacco consumption (never-smoker; ex-smoker; current light smoker (1-14 g/day), current heavy smoker ( $\geqslant 15 \mathrm{~g} /$ day), dusty occupation (yes/ no), and place of birth, and of current residence in terms of asbestos exposure (none, moderate, heavy asbestos pollution). Among female patients, sparse data necessitated the combination of light and heavy smokers and moderate and heavy asbestos exposure at birth. It was decided to stratify the age of the patients into those under 54 years, and 55 years or older, rather than using the variable as a continuous one, given that age was in certain cases "lumped" by the responder to the nearest decade. Replacing the stratified variable with a continuous one did not materially change the results. A $\chi^{2}$ test for trend (one degree of freedom), adjusted for all the other stratification levels, was used to test for (two-tailed) significance across exposure levels. 


\section{Results}

A total of 288 male and 60 female incident patients with lung cancer and 183 male and 197 female controls were interviewed (total number of men $=471$, women $=257$, table 1 ). Men with lung cancer were on average 58.6 years old (SD 11.5) and not significantly different to controls (60.9 years, SD 18.4, $\mathrm{p}=$ 0.1 ). Women with lung cancer were on average older than controls (57.8 years, SD 11.4, v 48.6 years, $S D 12.9, \mathrm{p}=0.0001)$.

In men there was an increased risk (OR) of developing lung cancer related to smoking: 2.2 $(95 \% \mathrm{CI}=1.0$ to 4.6$)$ in ex-smokers, $9.8(95 \%$ $\mathrm{CI}=5.9$ to 16.4$)$ in light smokers, and 12.0 $(95 \%$ CI $=6.5$ to 22.3$)$ in heavy smokers. In women the risk of developing lung cancer was $5.8(95 \% \mathrm{CI}=1.3$ to 25.8$)$ in ex-smokers, and $5.5(95 \% \mathrm{CI}=2.6$ to 11.3$)$ in current smokers.

Work in a dusty industry showed an elevated risk of developing lung cancer in men $(\mathrm{OR}=$ $3.2,95 \% \mathrm{CI}=1.8$ to 5.8 ) but, in women, work in this type of industry was almost protective ( $\mathrm{OR}=0.5,95 \% \mathrm{CI}=0.3$ to 1.1 ).

Although an elevated relative risk (RR) of developing lung cancer was found related to the use of wood or coal in the house, this was not significant in either men $(\mathrm{OR}=1.9,95 \%$ $\mathrm{CI}=0.9$ to 3.3$)$ or women $(\mathrm{OR}=1.4,95 \% \mathrm{CI}$ $=0.6$ to 3.2 ), but by combining data for men and women a significant association between lung cancer and indoor pollution was found $(\mathrm{RR}=2.0,95 \% \mathrm{CI}=1.1$ to 3.6$)$.

Men currently resident in a moderately polluted asbestos area had a significant 2.1-fold increase in the risk (OR) of developing lung cancer $(95 \%$ CI $=1.0$ to 4.4$)$ and male residents of heavy asbestos-polluted areas had a 2.8 -fold increase $(95 \% \mathrm{CI}=0.7$ to 10.4$)$ in risk. Female residents of combined moderately and heavily polluted asbestos areas also showed increases in the risk of developing lung cancer $(\mathrm{OR}=2.4,95 \% \mathrm{CI}=0.7$ to 7.9$)$. Three women and no controls were born in areas of heavy asbestos pollution. Men born in moderate or heavily polluted asbestos areas also had elevated risks in relation to lung cancer $(\mathrm{OR}=$ $2.9(95 \% \mathrm{CI}=1.2$ to 6.7$)$ and $3.1(95 \% \mathrm{CI}=$ 0.4 to 21.4 ), respectively).

Combining the male and female data and adjusting by age group, sex, dust, and wood fuel in the regression models resulted in an OR of 2.1 (95\% CI $=1.3$ to 3.8$)$ among current residents of asbestos polluted areas and an OR of 2.8 (95\% CI = 1.5 to 5.4$)$ for people born in asbestos-polluted areas (that is, moderate and heavy $v$ none). No significant changes in the risk (adjusted for dust and fuel use) of developing lung cancer in relation to smoking were detected in those born in or out of asbestos-contaminated areas (OR for eversmokers to never-smokers $=5.2(95 \% \mathrm{CI}=1.9$ to 14.3 ) and 8.6 (95\% CI $=5.8$ to 13.2$)$, respectively).

\section{Discussion}

Prevalence rates of current smokers of $32.9 \%$ in the male control group are comparable to recent national prevalence survey data from the Northern Province $(38 \%),{ }^{4}$ and data on ever-smokers from an annual marketing survey of $40.4 \%$ (South African Advertising Research Foundation 1998, unpublished data) (compared with $44.4 \%$ in ever-smokers in this study). Data among villagers in a remote rural district showed a prevalence of current smokers of $48 \%$ and of ever-smokers of $65 \% .^{5}$ In female controls, smoking rates were similar $(2.5 \%)$ to those found from the national prevalence survey $\left(2.1 \%\right.$ in women $\left.{ }^{4}\right)$, and the prevalence of smoking in a rural district in the Northern Province was $0.5 \%$ in women. ${ }^{5}$ Data from an annual marketing survey shows a prevalence of $1.8 \%$ for female ever-smokers in 1995 (South African Advertising Research Foundation, unpublished data, 1998) compared with this study of $3.5 \%$.

Age specific breakdowns of the prevalence surveys were not available but the data suggest that the control group chosen in this study was adequate for the purpose, and that no obvious biases exist in the self-reporting of tobacco use in this context. The same approach was also successfully used by Parkin et $\mathrm{al}^{2}$ in the study in Bulawayo so the data are at least comparable to the only other study on lung cancer and smoking in sub-Saharan Africans.

Lung cancer comprised $7.5 \%$ of all cancers in men and $0.4 \%$ of all cancers in women in the 1960s in three rural hospitals of the former Northern Transvaal (now the Northern Province). ${ }^{11}$ One of these was Elim Hospital where there is now an extant cancer registry. At Elim (1991-1994), lung cancer comprised $6.7 \%$ of all cancers in men, with no cases in women. These data only cover a small proportion of the province's population $(n=180000)$ but suggest that no significant increases in lung cancer have been seen, at least in the rural areas covered by these registries. Data from the (urban) Bulawayo cancer registry in Zimbabwe (300 km away) between 1963 and 1977 showed lung cancer rates in African men to be higher $^{2}$ (world standardised incidence rate $=$ $48.4 / 100000$ in men and 3/100000 in women).

Data on cancer incidence in Africa are scanty, but suggest that urban lung cancer incidence rates may be higher than rural rates, possibly related to more prolonged exposure to cigarette consumption in urban centres. The duration of tobacco consumption has been shown to be more important than the amount smoked. ${ }^{12}$ It is then probable that the data from Bulawayo were gathered at a time (1963-1977) when the tobacco epidemic had just started showing an effect in southern Africa. This may explain the lower risks (odds ratios) of developing lung cancer related to $15 \mathrm{~g}$ of tobacco consumption found in Bulawayo men (five-fold), compared with this study (12.6-fold).

The association between smoking and lung cancer has not been previously described for African women. In this study the relative risk of developing lung cancer related to smoking in women was 5.5. In men and women the risks of developing lung cancer related to smoking is reminiscent of risks observed in women in developed countries in the late 1960s and 
1970 s. $^{13}$ There were eight women who were heavy smokers and no controls, suggesting even higher risks in this group, although this needs to be reconfirmed by further work. There has been some evidence that female smokers may be more susceptible or at higher risk of developing lung cancer than $\mathrm{men}^{14}$ but the reasons for this are unknown.

Household use of wood or coal as fuel showed a significant two-fold risk related to lung cancer when data for men and women were combined. Many people use wood or coal for heating or cooking in this region $(82 \%$ of controls) so this association needs to be pursued more fully in larger studies.

The significant 3.4-fold increased risk of lung cancer which was found in men working in a dusty industry needs to be studied in more detail. This was not the case in women, presumably because they work in less dusty occupations within the industry.

Increased (multiplicative) risks of developing lung cancer related to asbestos exposure and smoking have been described elsewhere. ${ }^{15}$ Significantly elevated risks (approximately three-fold) of developing lung cancer in both sexes were detected here related to exposure to asbestos at birth or subsequently. However, no increased risk of developing lung cancer was detected in those environmentally exposed to asbestos related to smoking status. It must be noted that the asbestos exposure categories used are crude (for example, sharing the same postal code as a mine) and a more accurate classification of place of birth will be necessary.

In a South African geographical study ${ }^{16}$ of the white and "coloured" (mixed race) population living in the crocidolite asbestos rich districts of the Northern Cape province, standardised mortality rates (SMRs) for lung cancer were elevated for all groups, but were significant for white men $(S M R=1.75)$ and coloured women $(S M R=2.47)$. In the Bulawayo study, ${ }^{2}$ no increase in lung cancer risk was found related to work in asbestos mines, but in Zimbabwe the principal asbestos mined was chrysotile and the relation between this fibre type and lung cancer is not consistent ${ }^{17}$ although some tremolite has been found in Zimbabwean chrysotile. In South Africa, where all three major types of asbestos were mined, excess lung cancer risks related to asbestos exposure have been found in white miners $(\mathrm{SMR}=1.4$ for amosite and 2.0 for crocidolite $)^{18}$ but no similar studies have been conducted in black asbestos mine workers.

If the prevalence of asbestos exposure in the control population reflects the background exposure to environmental exposure to asbestos in this province, then about $4 \%$ of the African population in this province currently lives in areas where asbestos was mined. Controls need to be placed on curbing further erosion and airborne contamination of asbestos tailing dumps in this province.

More importantly the tobacco epidemic, although already evident, still has to show its full effect here. Only a small proportion of women smoke and it would be ideal if this pro- portion remained static or in both sexes began to diminish over time. Of course, by limiting the study to lung cancer, no data are available on the importance of tobacco consumption on the two dozen other illnesses found to be associated with the habit (and this now includes tuberculosis).$^{19}$ It is clear that further research is required to quantify the relative importance of smoking and environmental exposure to asbestos and lung cancer and other tobacco attributable diseases, especially in black women in South Africa.

This study was funded by the South African Medical Research Council (SAMRC). The Cancer Epidemiology Unit and the National Cancer Registry are funded by the Department of Health, the South African Institute for Medical Research and the Cancer Association of South Africa. We would like to thank Ms Engela Ackermann and Engela Gerber of the SAMRC for data entry, Ms Marcelle Arnold, Ms Alicia Thompson, Ms Karen Koetsie and Ms Karen Peffer of the University of the Witwatersrand Bursary Scheme for data coding, Ms Janet Knuppel for typing the manuscript, Dr Marianne Felix and Dr Knuppel for typing the manuscript, Dr Marianne Felix and Dr Eva Hnidzo of the National Center for Occupational Health, and Dr Max Parkin, IARC, for their advice and comments. We would also like to acknowledge the UICC for highlighting the need for studies on tobacco to be conducted in Africa. Henri Carrara was a recipient of an UICC ICRETT Fellowship Award in 1997.

1 International Agency for Research on Cancer Working Group. IARC monographs on the evaluation of the carcinogenic risks to humans: tobacco smoking. Vol 38. Lyon: World Health Organization, IARC, 1986

2 Parkin DM, Vizcaino AP, Skinner MEG, et al. Cancer patterns and risk factors in the African population of Southwestern Zimbabwe, 1963-1977. Cancer Epidemiol Biomarkers Prev 1994;3:537-47.

3 Republic of South Africa Department of Health. Health and population related indicators per province in South Africa. Pretoria: Government Printer, 1994

4 Reddy P. Meyer-Weitz A, Yach D. Smoking status, knowledge of health effects and attitudes towards tobacco control in South Africa. S Afr Med F 1996;86:1389-93.

5 Felix M. Environmental asbestos exposure and respiratory disease in South Africa. PhD thesis. Johannesburg: University of The Witwatersrand, 1997.

6 Myers J, Aron A, Macun I. Asbestos and asbestos related disease: the South African case. Int $\mathcal{f}$ Health Serv 1978; 17:651-65.

7 Sitas F, Blaauw D, Terblanche $\mathrm{M}$, et al. Incidence of histologically diagnosed cancer in South Africa, 1992. Johannesburg: National Cancer Registry, South African Institute for Medical Research, 1997.

8 Barra S, Baron AE, Franceschi S, et al. Cancer and non cancer controls in studies on the effect of tobacco and alcohol consumption. Int $\mathcal{F}$ Epidemiol 1991;20:845-51.

9 Central Statistical Services. Standard classification of occupations. Report 09-90-01. Pretoria: Government Printer, 1986.

10 SAS Institute Inc. SAS/STAT user's guide, version 6, 4th ed, vol 2. Cary, North Carolina: SAS Institute Inc, 1989.

11 Higginson J, Oettlé AG. Cancer incidence in the Bantu and "Cape Coloured" races of South Africa: report of a cancer survey in the Transvaal (1953-55). I Natl Cancer Inst 1960;24:589-671.

12 Peto R. Influence of dose and duration of smoking on lung cancer rates. In: Zaridze D, Peto R, eds. Tobacco, a major international health hazard. Lyon: International Agency for Research on Cancer, Scientific Publication No 74, 1986.

13 Parkin DM, Sasco AJ. Lung cancer: world-wide variation in occurrence and proportion attributable to tobacco use. Lung Cancer 1993;9:1-16.

14 Risch HA, Howe GR, Fain M, et al. Are female smokers at higher risk for lung cancer than male smokers? A case control analysis by histology type. Am $\mathcal{F}$ Epidemiol 1993; 138:281-93.

15 Selikoff IJ. Constraints in estimating occupational contributions to current cancer mortality in the United States. In: Peto R, Schneidermann M, eds. Ouantification of occupational cancer. Banbury Report No 9:3-13. Cold Spring Harbor, New York: Cold Spring Laboratory, 1981.

16 Botha JL, Irwig LM, Strebel P. Excess mortality from mesothelioma, lung and stomach cancers in the crocidolite mining districts in South Africa. Am $f$ Epidemiol 1986;123:30-40.

17 Churg A, Vedal S. Fiber burden and patterns of asbestosrelated disease in workers with heavy mixed amosite and
chrysotile exposure. Am $\mathcal{f}$ Respir Crit Care Med 1994; 150:663-69.

18 Sluis-Cremer GK, Liddell FDK, Logan WPD, et al. The mortality of amphibole miners in South Africa, 19461980. Br F Ind Med 1992;49:566-75.

19 Doll R, Peto R, Wheatley K, et al. Mortality in relation to smoking: 40 years' observations on male British doctors. $B M F$ 1994; 309:901-11 